\title{
Quantification of NAD(P)H in cyanobacterial cells by a phenol extraction method
}

\author{
Kenya Tanaka ${ }^{1} \cdot$ Ginga Shimakawa $^{2} \cdot$ Hiro Tabata $^{1} \cdot$ Shoko Kusama $^{1} \cdot$ Chikahiro Miyake $^{3} \cdot$ Shuji Nakanishi $^{1,2}$
}

Received: 25 December 2020 / Accepted: 12 April 2021 / Published online: 2 May 2021

(c) The Author(s) 2021

\begin{abstract}
In photosynthetic organisms, it is recognized that the intracellular redox ratio of NADPH is regulated within an appropriate range for the cooperative function of a wide variety of physiological processes. However, despite its importance, there is large variability in the values of the NADPH fraction [NADPH/(NADPH $\left.\left.+\mathrm{NADP}^{+}\right)\right]$quantitatively estimated to date. In the present study, the light response of the NADPH fraction was investigated by applying a novel NADP $(\mathrm{H})$ extraction method using phenol / chloroform / isoamyl alcohol (PCI) in the cyanobacterium Synechocystis sp. PCC 6803. The light response of $\mathrm{NADP}(\mathrm{H})$ observed using PCI extraction was qualitatively consistent with the $\mathrm{NAD}(\mathrm{P}) \mathrm{H}$ fluorescence time course measured in vivo. Moreover, the results obtained by PCI extraction and the fluorescence-based methods were also consistent in a mutant lacking the ability to oxidize $\mathrm{NAD}(\mathrm{P}) \mathrm{H}$ in the respiratory chain, and exhibiting a unique NADPH light response. These observations indicate that the PCI extraction method allowed quantitative determination of NADP(H) redox. Notably, the PCI extraction method showed that not all NADP $(\mathrm{H})$ was oxidized or reduced by light-dark transition. Specifically, the fraction of NADPH was $42 \%$ in the dark-adapted cell, and saturated at $68 \%$ in light conditions.
\end{abstract}

Keywords NADPH $\cdot$ Photosynthesis $\cdot$ Cyanobacteria $\cdot$ Quantitative determination $\cdot$ Intracellular redox state

\section{Introduction}

The redox pair $\mathrm{NADP}^{+} / \mathrm{NADPH}$ is involved in various reactions in photosynthetic organisms. $\mathrm{NADP}^{+}$is the terminal electron acceptor in the photosynthetic electron transport chain (PETC) and is converted to NADPH under light conditions. The NADPH thus generated supports biosynthetic and antioxidant systems by serving as a reducing driver for various enzymes including glyceraldehyde 3-phosphate dehydrogenase (GAPDH), NADPH-thioredoxin reductase (NTR), glutathione reductase (GR), etc. (Raines 2003;

Shuji Nakanishi

nakanishi@chem.es.osaka-u.ac.jp

1 Graduate School of Engineering Science, Osaka University, 1-3 Machikaneyama, Toyonaka, Osaka 560-8631, Japan

2 Research Center for Solar Energy Chemistry, Osaka University, 1-3 Machikaneyama, Toyonaka, Osaka 560-8631, Japan

3 Department of Biological and Environmental Science, Faculty of Agriculture, Graduate School of Agricultural Science, Kobe University, 1-1 Rokkodai, Nada, Kobe 657-8501, Japan
Hishiya et al. 2008; Yoshida and Hisabori 2016; Vogelsang and Dietz 2020). The oxidized form $\left(\mathrm{NADP}^{+}\right)$also functions as an essential co-factor for glucose-6-phosphate dehydrogenase (G6PDH), 6-phosphogluconate dehydrogenase (6PGDH), and isocitrate dehydrogenase (ICD) in primary metabolism (Muro-Pastor and Florencio 1992; Ishikawa and Kawai-Yamada 2019). Given that the NADP ${ }^{+} / \mathrm{NADPH}$ redox ratio, a critical factor influencing various biological processes, can vary with changes in the lighting conditions, it is vitally important to quantitatively determine the intracellular concentrations of $\mathrm{NADP}(\mathrm{H})$ for a deeper understanding of the physiology of photosynthesis.

Fluorescence detection of NADPH is a representative in vivo method for measuring light-responsive changes in NADPH concentrations. For example, it has been shown that NADPH was produced or consumed in the sub-second order by light-dark transitions (Mi et al. 2000; Kauny and Sétif 2014; Shaku et al. 2016). However, the fluorescent yield of NADPH changes depending on the peripheral environment (Latouche et al. 2000; Kauny and Sétif 2014). Importantly, $\mathrm{NADP}^{+}$(the counterpart of NADPH) does not emit fluorescence. Therefore, the in vivo fluorescence-based technique cannot directly assess the $\mathrm{NADP}^{+}$/ 
NADPH redox ratio or the absolute amount of NADP $(H)$. In contrast, the concentration of $\mathrm{NADP}(\mathrm{H})$ can be quantitatively measured following cellular extraction. In fact, previous studies have attempted to quantify the concentration of $\operatorname{NADP}(\mathrm{H})$ and the redox ratio in vitro. However, the reported values of the in vitro studies differ widely (Table 1). The redox ratio estimated by in vitro extraction methods must be consistent with the dynamic behavior of NADPH fluorescence; however, no studies have been undertaken to demonstrate consistency between in vivo and in vitro measures.

In the present work, we quantified the amount of NADP $(\mathrm{H})$ in Synechocystis sp. PCC 6803 (hereafter Synechocystis) in vitro using a phenol/chloroform/isoamyl alcohol (PCI) solution to deactivate undesirable enzymatic reactions, and evaluated the obtained values against the dynamic behavior of $\mathrm{NAD}(\mathrm{P}) \mathrm{H}$ fluorescence. Importantly, the light-responsive changes in $\mathrm{NADP}(\mathrm{H})$ determined using the PCI extraction method were consistent with the results of in vivo $\mathrm{NAD}(\mathrm{P}) \mathrm{H}$ fluorescence measurements, indicating the validity of the novel extraction protocol. Development of this novel protocol has revealed that the fraction of NADPH $\left[\mathrm{NADPH} /\left(\mathrm{NADPH}+\mathrm{NADP}^{+}\right)\right]$in Synechocystis cells in light conditions reached $68 \%$, which was unchanged over wide range of light intensity.

\section{Materials and methods}

\section{Bacterial strains and cell culture conditions}

We used the following Synechocystis strains: wild-type and $\Delta n d h D 1 / 2$ (Ohkawa et al. 2000). These strains were grown and maintained on solid (1.5\% Bacto agar) BG-11 medium plates. For pre-culture, cells from the agar plate were inoculated into $30 \mathrm{~mL}$ liquid BG-11 medium in a $100-\mathrm{mL}$ flask and grown at $30^{\circ} \mathrm{C}$ with air bubbling under white light illumination at an intensity of $20 \mu \mathrm{mol} \mathrm{m} \mathrm{m}^{-2} \mathrm{~s}^{-1}$. For the main culture, the pre-culture was inoculated to achieve an optical density of 0.02 at $730 \mathrm{~nm}\left(\mathrm{OD}_{730}\right)$ in $30 \mathrm{~mL} \mathrm{BG}-11$. Other conditions were the same as those in pre-culture. Fig. S1 shows the growth curves of the main culture measured at an optical density of $730 \mathrm{~nm}$ and the chlorophyll concentration. To determine the chlorophyll concentration, the cells were harvested by centrifugation at $12,000 \times \mathrm{g}$ for $5 \mathrm{~min}$ and suspended in $100 \%$ methanol. The suspension was then

Table 1 Comparison of $\mathrm{NADP}(\mathrm{H})$ measurements in cyanobacteria and their results

\begin{tabular}{|c|c|c|c|c|c|c|c|}
\hline Species & $\mathrm{NADPH}^{3}$ & $\mathrm{NADP}^{+3}$ & $\begin{array}{l}\text { NADPH frac- } \\
\text { tion }\end{array}$ & $\begin{array}{l}\text { Growth condi- } \\
\text { tion }\end{array}$ & $\begin{array}{l}\text { Extracted condi- } \\
\text { tion }\end{array}$ & $\begin{array}{l}\text { Extraction } \\
\text { method }\end{array}$ & References \\
\hline Synechococcus ${ }^{1}$ & $373 \mu \mathrm{M}$ & $276 \mu \mathrm{M}$ & 0.575 & 6 h Light & & Acid/Base & $\begin{array}{c}\text { Tamoi et al. } \\
\text { (2005) }\end{array}$ \\
\hline Synechococcus $^{1}$ & $306 \mu \mathrm{M}$ & $177 \mu \mathrm{M}$ & 0.634 & $6 \mathrm{~h}$ Dark & & Acid/Base & $\begin{array}{l}\text { Tamoi et al. } \\
\text { (2005) }\end{array}$ \\
\hline Synechocystis ${ }^{2}$ & $\begin{array}{l}4.8 \\
\mu \mathrm{mol} / \mathrm{mg} \mathrm{Chl}\end{array}$ & $\begin{array}{l}1.6 \mu \mathrm{mol} / \mathrm{mg} \\
\mathrm{Chl}\end{array}$ & 0.750 & $\begin{array}{l}\text { Photoauto- } \\
\text { trophic }\end{array}$ & & Beads & $\begin{array}{l}\text { Cooley and } \\
\text { Vermaas } \\
(2001)\end{array}$ \\
\hline Synechocystis ${ }^{2}$ & $138 \mathrm{nmol} / \mathrm{g} \mathrm{FW}$ & $99.6 \mathrm{nmol} / \mathrm{g} \mathrm{FW}$ & 0.581 & $\begin{array}{l}\text { Photoauto- } \\
\text { trophic }\end{array}$ & & Organic solvent & $\begin{array}{l}\text { Takahashi et al. } \\
\text { (2008) }\end{array}$ \\
\hline Synechocystis ${ }^{2}$ & $88.0 \mathrm{nmol} / \mathrm{g} \mathrm{FW}$ & $70.3 \mathrm{nmol} / \mathrm{g} \mathrm{FW}$ & 0.556 & $\begin{array}{l}\text { Photomixo- } \\
\text { trophic }\end{array}$ & & Organic solvent & $\begin{array}{l}\text { Takahashi et al. } \\
\text { (2008) }\end{array}$ \\
\hline Synechocystis ${ }^{2}$ & $43.6 \mathrm{nM}$ & $6260.8 \mathrm{nM}$ & 0.0069 & $\begin{array}{l}\text { Photoauto- } \\
\text { trophic }\end{array}$ & & Organic solvent & $\begin{array}{l}\text { Osanai et al. } \\
\text { (2014) }\end{array}$ \\
\hline Synechocystis $^{2}$ & $58.8 \mathrm{nmol} / \mathrm{g} \mathrm{FW}$ & $69.0 \mathrm{nmol} / \mathrm{g} \mathrm{FW}$ & 0.460 & $\begin{array}{l}\text { Photoauto- } \\
\text { trophic }\end{array}$ & & Acid/Base & $\begin{array}{l}\text { Ishikawa et al. } \\
\text { (2016) }\end{array}$ \\
\hline \multirow[t]{2}{*}{ Synechocystis $^{2}$} & $17.9 \mathrm{nmol} / \mathrm{g} \mathrm{FW}$ & $65.9 \mathrm{nmol} / \mathrm{g} \mathrm{FW}$ & 0.214 & $\begin{array}{l}\text { Photoauto- } \\
\text { trophic }\end{array}$ & & Acid/Base & $\begin{array}{l}\text { Ishikawa et al. } \\
\text { (2019) }\end{array}$ \\
\hline & $59.9 \mathrm{nM} / \mathrm{OD}$ & $82.0 \mathrm{nM} / \mathrm{OD}$ & 0.422 & & Dark-adapted & & This study \\
\hline \multirow[t]{2}{*}{ Synechocystis ${ }^{2}$} & $87.4 \mathrm{nM} / \mathrm{OD}$ & $42.0 \mathrm{nM} / \mathrm{OD}$ & 0.677 & $\begin{array}{l}\text { Photoauto- } \\
\text { trophic }\end{array}$ & Light-irradiated & PCI & This study \\
\hline & $45.3 \mathrm{nM} / \mathrm{OD}$ & $98.9 \mathrm{nM} / \mathrm{OD}$ & 0.315 & & $\begin{array}{l}\text { Onset of dark- } \\
\text { ness }\end{array}$ & & This study \\
\hline
\end{tabular}

${ }^{1}$ Synechococcus elongatus PCC 7942

${ }^{2}$ Synechocystis sp. PCC 6803

${ }^{3}$ For amount values of $\mathrm{NADP}(\mathrm{H})$ in this study, unit can be converted by following Eqs. $1 \mathrm{nM} / \mathrm{OD}=0.25 \mathrm{nmol} / \mathrm{mg} \mathrm{Chl}$ (using value of $4.0 \mathrm{mg}$ Chl/L/OD from Fig. S1) 
centrifuged at $12,000 \times \mathrm{g}$ for $5 \mathrm{~min}$, followed by measurement of absorption at $665 \mathrm{~nm}$. The chlorophyll $a$ concentration was calculated according to a previously described method (Grimme and Boardman 1972).

\section{NAD(P)H fluorescence measurements}

The in vivo $\mathrm{NAD}(\mathrm{P}) \mathrm{H}$ fluorescence originating from $\mathrm{NAD}(\mathrm{P}) \mathrm{H}$ was measured using the NADPH/9-AA module of a Dual-PAM-100 instrument (Heinz Walz, Effeltrich, Germany) (Kauny and Sétif 2014; Shimakawa et al. 2018). The reaction mixtures $(2 \mathrm{~mL})$ contained fresh BG-11 medium (pH 7.5) and cyanobacterial cells ( $2.5 \mu \mathrm{g}$ chlorophyll $\left.\mathrm{mL}^{-1}\right)$. The NADPH/9-AA module consists of an emitter unit (DUAL-ENADPH) and a detector unit (DUAL-DNADPH). NADPH fluorescence was excited by UV-A (365 nm) from the DUAL-ENADPH unit and detected by a blue-sensitive photomultiplier with a filter transmitting light between 420 and $580 \mathrm{~nm}$ in the DUAL-DNADPH unit. The measured light intensity was on a scale from 1 to 20 , and the intensity was set at 10 in this study. The measuring light frequency in the absence and presence of red actinic light was set at $200 \mathrm{~Hz}$ and 5,000 Hz, respectively.

\section{Pyridine nucleotides extraction}

PCI solution was prepared as follows. Crystalline phenol was melted in a $65^{\circ} \mathrm{C}$ water bath, followed by the addition of an equal volume of $0.5 \mathrm{M}$ Tris-HCl buffer ( $\mathrm{pH}$ 8.0). After vigorous mixing, the upper water phase was removed and $0.1 \mathrm{M}$ Tris- $\mathrm{HCl}$ ( $\mathrm{pH}$ 8.0) was added. The same amount of chloroform/isoamyl alcohol $(24: 1 \mathrm{v} / \mathrm{v})$ solution as the phenol was added to obtain the PCI solution (phenol: chloroform: isoamyl alcohol 25:24:1 v/v). Pyridine nucleotides extraction was performed using about 5 to 6-day-old main cultures corresponding to $\mathrm{OD}_{730}=2-4$ (approx.) (Fig. S1). Before extraction, the cultures were maintained under darkness for an hour with air bubbling. After the dark adaptation, cells were harvested from the calculated volume of culture $(2 \mathrm{ml}$ $/ \mathrm{OD}_{730}$ ) by centrifugation at $12,000 \times \mathrm{g}$ for $3 \mathrm{~min}$. The cell pellet was suspended in $50 \mu \mathrm{L}$ of $1 \mathrm{mM} \mathrm{NaHCO}$. For the extraction from dark-adapted cells, $300 \mu \mathrm{L}$ PCI was added to the suspension followed by the addition of $250 \mu \mathrm{L}$ extraction buffer (approx. pH 10.4-11.0, production code: N509 or N510 Dojindo, Kumamoto Japan). For light-irradiated extraction, the cell suspension was transferred into a cuvette with $1 \mathrm{~mm}$ optical path to illuminate the cells. For actinic light, LED light source (pE-100wht, BioVision Technologies, Exton, PA, USA) was used through $550 \mathrm{~nm}$ long path filter. A $300-\mu \mathrm{L}$ aliquot of PCI was added to the suspension in the cuvette at various time points, followed by the addition of $250 \mu \mathrm{L}$ extraction buffer. The PCI suspension samples were centrifuged at $12,000 \times \mathrm{g}$ for $3 \mathrm{~min}$. Each upper water phase was transferred to a microtube and frozen quickly in liquid nitrogen.

For extraction without PCI, only extraction buffer was added to the cells. The cell suspension was frozen and thawed once for cell disruption. Proteins in the cell lysate were removed by ultrafiltration before NADP(H) measurements. Other extraction processes were same as those for PCI.

\section{Enzymatic pyridine nucleotides measurement}

For the PCI extraction samples, after thawing the pyridine nucleotides extraction, $250 \mu \mathrm{L}$ chloroform/isoamyl alcohol $(24: 1 \mathrm{v} / \mathrm{v})$ solution was added for further removal of phenol. The mixture was centrifuged at $12,000 \times \mathrm{g}$ for $5 \mathrm{~min}$ and the water layer was transferred into two microtubes for measurement of total pyridine nucleotides and reduced form of pyridine nucleotides (NADH and NADPH). The sample used for measuring reduced form of pyridine nucleotides was incubated at $60{ }^{\circ} \mathrm{C}$ for an hour to decompose oxidized form of pyridine nucleotides $\left(\mathrm{NAD}^{+}\right.$and $\left.\mathrm{NADP}^{+}\right)$in the sample solution $\left(\mathrm{NAD}^{+}\right.$and $\mathrm{NADP}^{+}$are unstable in heated alkaline solutions), while the sample used for measuring total pyridine nucleotides was kept on ice. For determination of the pyridine nucleotides concentration, the enzymatic cycling assay was performed according to the manufacturer's instructions (production code: $\mathrm{N} 509$ for $\mathrm{NAD}(\mathrm{H})$; N510 for $\operatorname{NADP}(\mathrm{H})$, Dojindo Kumamoto Japan). The principle of the enzymatic measurements was summarized in a review paper (Kern et al. 2014). Absorbance at $450 \mathrm{~nm}$ of each sample in a 96-well plate was measured on Infinite M200 Plate Reader (Tecan, Männedorf, Switzerland).

\section{Results}

\section{In vitro quantitation of $\mathrm{NADP}(\mathrm{H})$}

First, NADP(H) was extracted from dark-adapted Synechocystis cells using extraction buffer, and subsequently quantified according to the standard protocol of the commercially available assay kit (see Materials and Methods for details). Although $2.1 \mu \mathrm{M}$ of $\mathrm{NADP}^{+}$in the extraction buffer was confirmed to be present, the reduced form, NADPH, was not detected (Fig. 1a-1). To verify the possibility that NADPH was unexpectedly oxidized during the extraction process, extraction was performed using a buffer containing exogenous $1.5 \mu \mathrm{M} \mathrm{NADP}{ }^{+}$and $1.5 \mu \mathrm{M}$ NADPH as standards. The NADPH level was confirmed to be less than $1.5 \mu \mathrm{M}$ even for this sample (Fig. 1a-2). Notably, when only the exogenous $\mathrm{NADP}^{+} / \mathrm{NADPH}$ mixture was examined, the concentrations were accurately quantified (Fig. 1a-3). These 


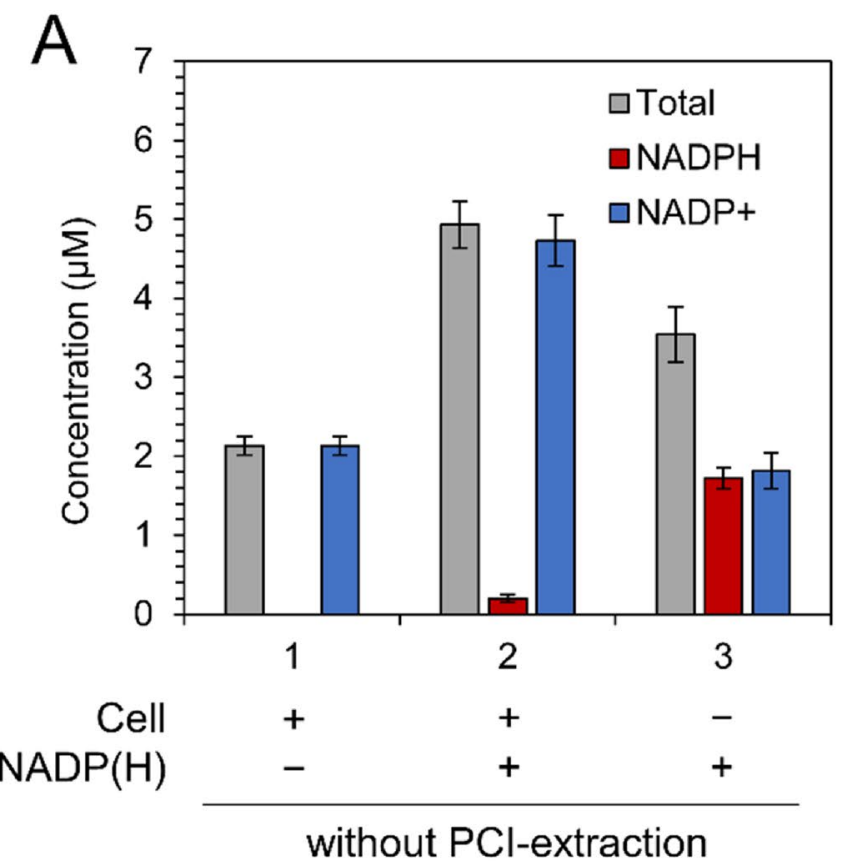

Fig. 1 Effect of PCI solution on NADP(H) extraction. NADP(H) concentration in the crude extracts processed (a) without and (b) with PCI. Sample numbers are indicated on the horizontal axes; No. 1:

results clearly indicated that components in the cell lysate oxidized NADPH during the extraction process.

Considering that non-enzymatic degradation of $\mathrm{NADP}(\mathrm{H})$ is negligible due to the very slow kinetics, Fig. 1a suggests that the cell lysate contains enzymes that accelerate the redox reactions related to NADP $(\mathrm{H})$ chemistry. To accurately quantify the intracellular $\mathrm{NADP}^{+} / \mathrm{NADPH}$ ratio, these proteins must be quickly inactivated during the extraction process. Therefore, NADP $(\mathrm{H})$ was extracted in the presence of a PCI, a protein scavenging agent widely used for extracting nucleic acids (hereafter, this protocol is called PCI extraction). In this case, although the total concentration of $\mathrm{NADP}^{+}$and NADPH was the same as that determined without PCI treatment, the NADPH value reached $0.8 \mu \mathrm{M}$ (Fig. 1b-1). When $1.5 \mu \mathrm{M}$ of exogenous NADP(H) was added following addition of PCI to the cells, the concentrations of NADPH and $\mathrm{NADP}^{+}$both increased by approximately $1.5 \mu \mathrm{M}$ (Fig. 1b-2). It was confirmed that PCI itself did not affect the measurement of exogenous NADP(H) (Fig. 1b-3) These results suggested that the intracellular concentrations of NADP $(\mathrm{H})$ can be quantitatively determined using the developed PCI extraction protocol.

\section{Comparison of in vivo and in vitro measurements}

To evaluate the validity of the PCI extraction protocol, the time-transient behavior of NADPH levels under varying irradiation conditions was compared with the results obtained

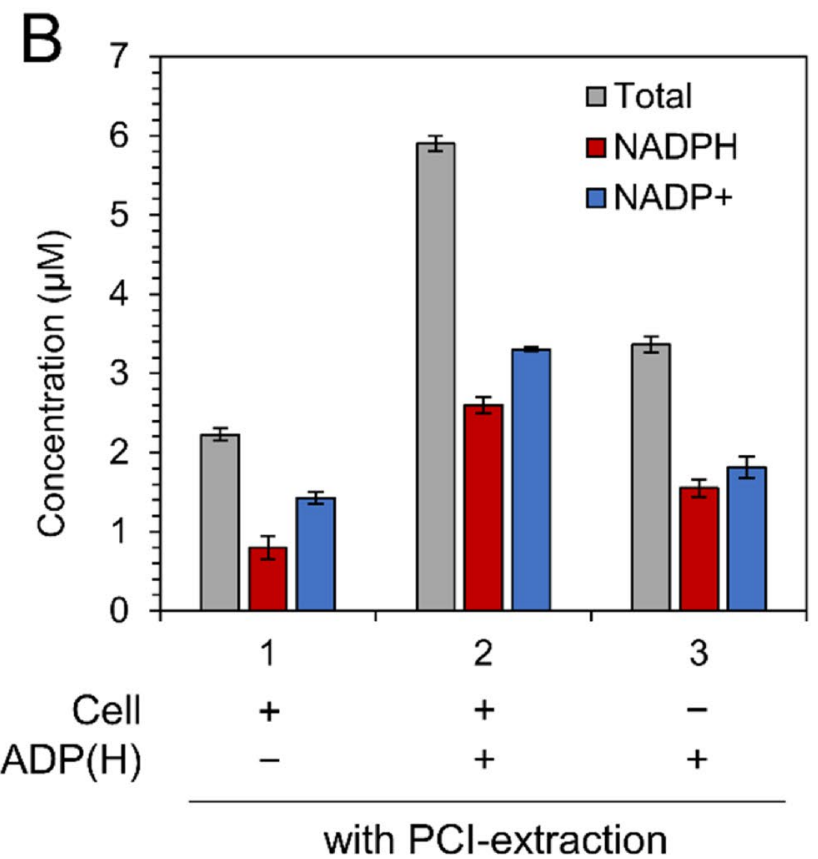

crude extracts from dark-adapted cells, No. 2: crude extracts containing exogenous $\mathrm{NADP}(\mathrm{H})$, No. 3: exogenous $\mathrm{NADP}(\mathrm{H})$. Values are means $\pm \mathrm{SD}$ (bars) of three biological replicates

using the $\mathrm{NAD}(\mathrm{P}) \mathrm{H}$ fluorescence measurement method. As shown in Fig. 2a, when the actinic light $\left(200 \mu \mathrm{mol} \mathrm{m}^{-2} \mathrm{~s}^{-1}\right)$ was turned on, the $\mathrm{NAD}(\mathrm{P}) \mathrm{H}$ fluorescence intensity rapidly increased (stage-II). When the light was turned off, the fluorescence intensity decreased and reached a minimum within $5 \mathrm{~s}$, subsequently increasing and stabilizing after $30 \mathrm{~s}$ (stage-III). This time-transient behavior is in good agreement with previous reports, and the decrease and increase of the fluorescence level after turning the light off in stage-III are considered to be due to NADPH consumption by the Calvin cycle and NADPH production by the oxidative pentose phosphate pathway (OPPP), respectively (Mi et al. 2000; Kauny and Sétif 2014). The fluorescence-based method can detect $\mathrm{NAD}(\mathrm{P}) \mathrm{H}$ responses to environmental light changes on a time scale of seconds.

Next, the range of variation in the amount of NADP $(H)$ was estimated using the PCI extraction method. PCI was added to cell suspension at three different points (Fig. 2a, points 1-3). Although the total amounts of NADP $(\mathrm{H})$ were the same for all three samples, the NADPH fraction changed depending on the stage (Figs. 2b, c). The observed fraction of NADPH was 0.42 for the dark-adapted cells, which increased to 0.68 following light irradiation $\left(600 \mu \mathrm{mol} \mathrm{m}^{-2} \mathrm{~s}^{-1}\right)$, and then decreased to 0.32 at the onset of darkness. The time-transient behavior of NADPH levels under light/dark perturbations deduced using the PCI extraction protocol agrees well with that obtained using fluorescence measurements. However, although this light-dependent changes of 

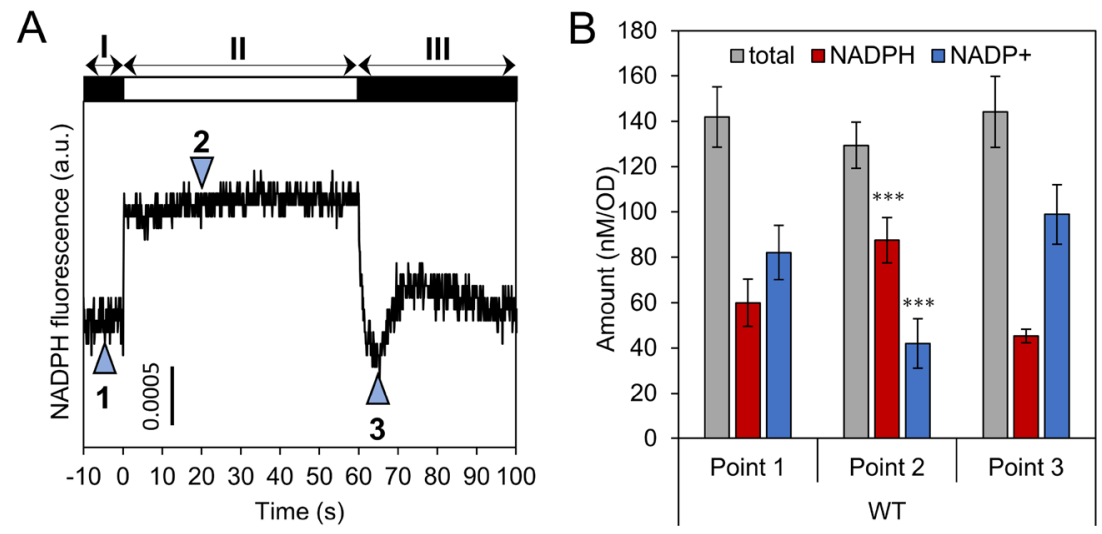

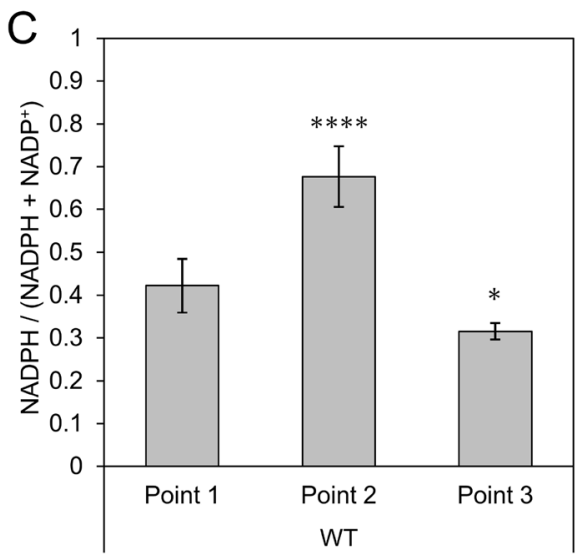

Fig. 2 Light response of NADP(H) in wild type (WT). (a) NAD(P) $\mathrm{H}$ fluorescence transients affected by 1 min illumination. White and black bars indicate light and dark condition, respectively. Points indicated by triangles with numbers correspond to three different states; point 1: after $1 \mathrm{~h}$ dark adaptation, point 2: $20 \mathrm{~s}$ after light irradiation $\left(200 \mu \mathrm{mol} \mathrm{m} \mathrm{m}^{-2} \mathrm{~s}^{-1}\right)$, point $3: 5 \mathrm{~s}$ after transition to the dark condition. $(\mathbf{b}, \mathbf{c}) \mathrm{NADP}(\mathrm{H})$ contents and NADPH frac-

fluorescence is generally considered to be originated from NADPH variations, there is a possibility that variation of NADH amount also affects the fluorescence behavior because the fluorescence measurement used in this study cannot distinguish fluorescence signal from NADPH and $\mathrm{NADH}$. To verify light response of $\mathrm{NADH}, \mathrm{NAD}(\mathrm{H})$ was also quantified by using PCI method. As a result, the amount and fraction of NADH was unchanged over the light-dark tion against total $\mathrm{NADP}(\mathrm{H})$ content in WT were obtained by adding PCI to the cell suspension at each time point. The light intensity of $600 \mu \mathrm{mol} \mathrm{m} \mathrm{m}^{-2} \mathrm{~s}^{-1}$ was used. Values are means \pm SD (bars) of about 3-6 biological replicates. Significant differences from darkadapted conditions were evaluated by a Student's t test $\left({ }^{*} P<0.05\right.$, $* * * P<0.001, * * * * P<0.0001)$

transition, indicating that time-transient changes of the fluorescence observed in this time scale was attributed to the variation of NADPH alone (Fig. 3).

The fraction of NADPH in light conditions $\left(600 \mu \mathrm{mol} \mathrm{m} \mathrm{m}^{-2} \mathrm{~s}^{-1}\right)$ was measured as $0.68 \pm 0.07$ in Fig. $2 \mathrm{c}$, and it seems that there is a room for $\operatorname{NADP}(\mathrm{H})$ to be more reductive. To evaluate the maximum reduction level of $\mathrm{NADPH}$, we investigated light intensity dependency of
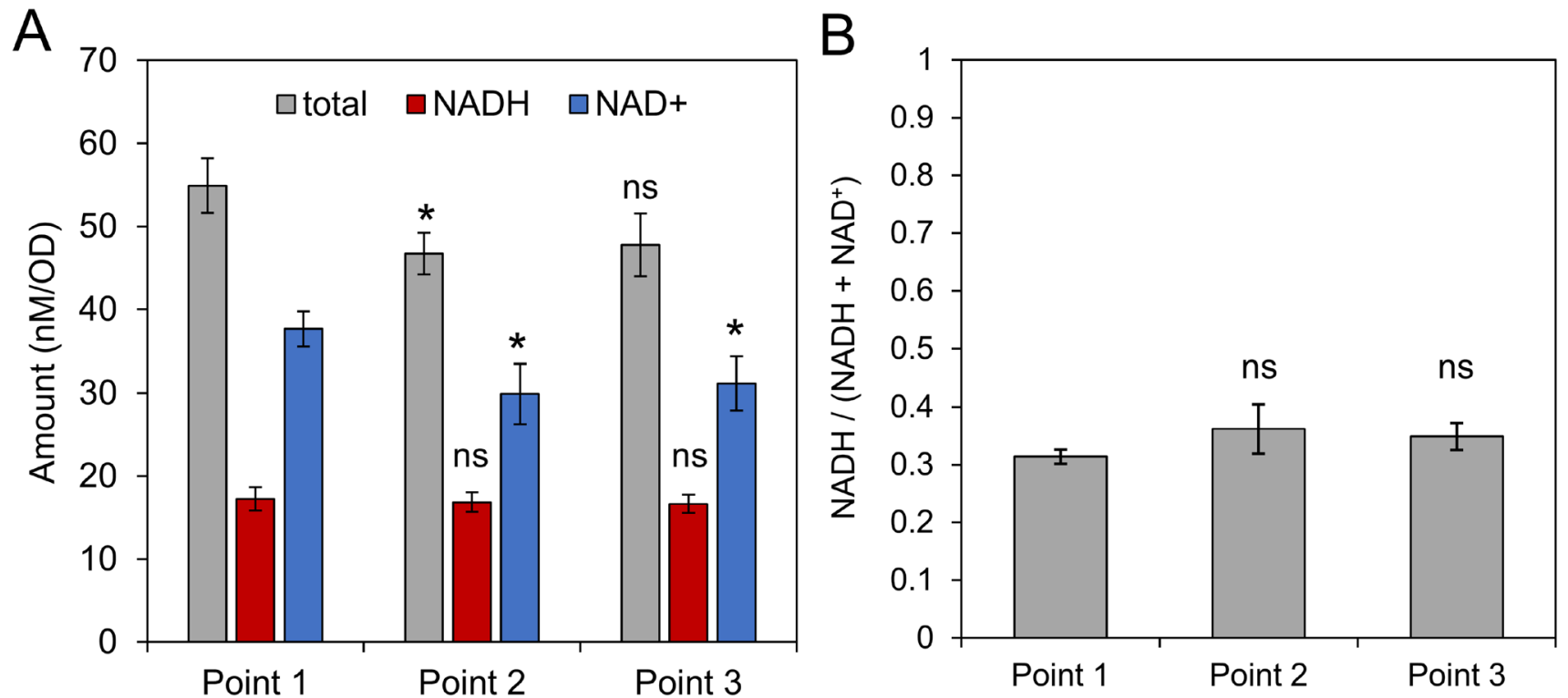

Fig. 3 Effect of light irradiation on $\mathrm{NAD}(\mathrm{H})$ in wild type (WT). (a) $\mathrm{NAD}(\mathrm{H})$ contents and (b) $\mathrm{NADH}$ fraction against total $\mathrm{NAD}(\mathrm{H})$ content in WT were obtained by adding PCI to the cell suspension at each time point same as Fig. 2. The light intensity of

$800 \mu \mathrm{mol} \mathrm{m} \mathrm{m}^{-2} \mathrm{~s}^{-1}$ was used. Values are means \pm SD (bars) of 3 biological replicates. Significant differences from dark-adapted conditions were evaluated by a Student's t test (ns: not significant; $* P<0.05)$ 
NADPH level by both fluorescence and PCI extraction methods. Interestingly, increasing light intensity more than $20 \mu \mathrm{mol} \mathrm{m} \mathrm{m}^{-2} \mathrm{~s}^{-1}$ did not give a significant rise on the fluorescence intensity, suggesting that redox state of NADP(H) was saturated at very weak light intensity (Figs. 4a-c). In fact, light intensity dependence of NADPH fraction measured by the PCI extraction method showed the similar saturation behavior (Fig. 4d). These results indicate that maximum photoreduced fraction of NADPH was $68 \%$, and approximately $32 \% \mathrm{NADP}(\mathrm{H})$ is kept oxidized even in light conditions by unknown mechanism(s) in this experimental condition.
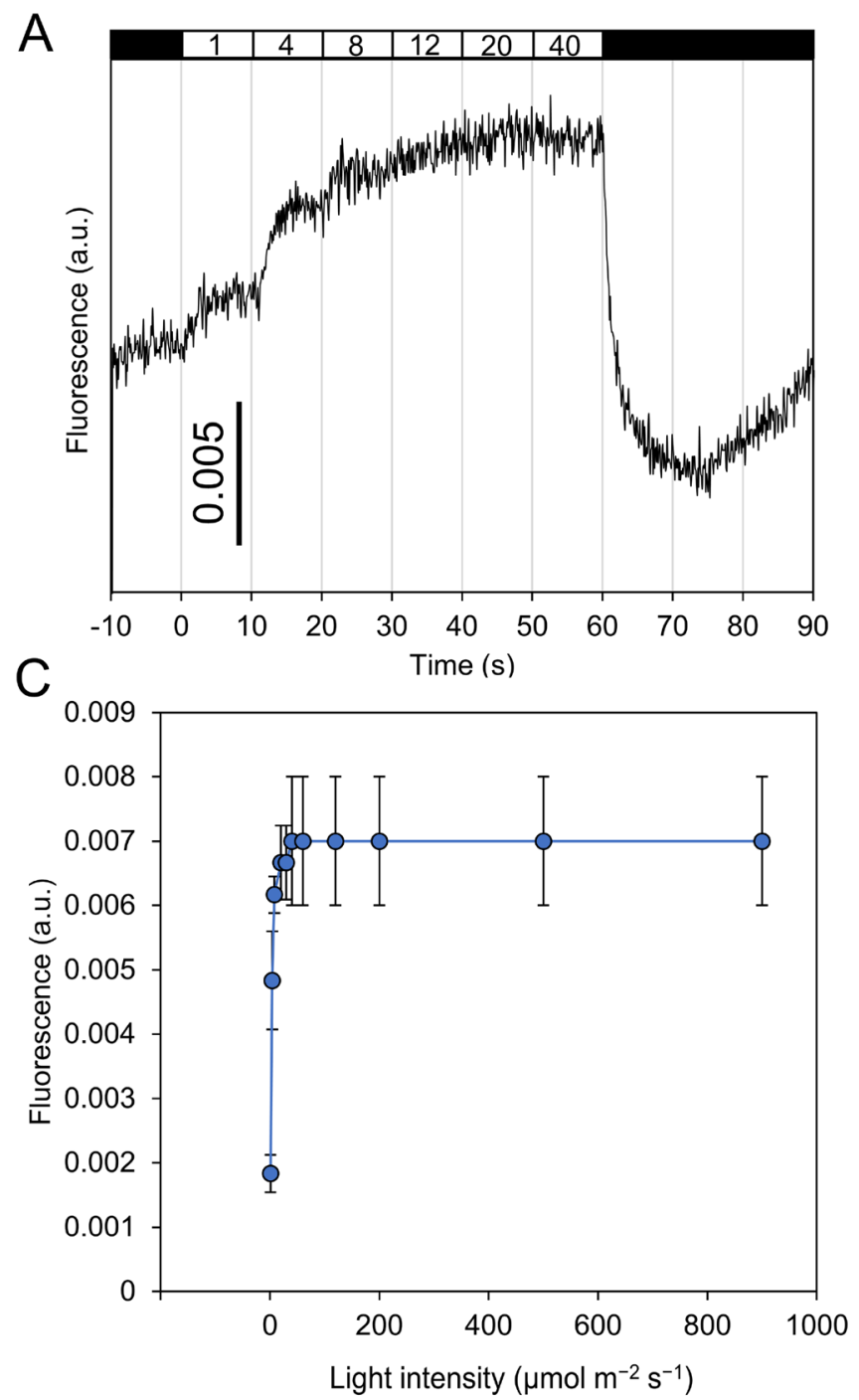

Fig. 4 Effect of light intensity on NADPH reduction level. (a, b) $\mathrm{NAD}(\mathrm{P}) \mathrm{H}$ fluorescence trace measured under different light intensities. White and black bars indicate light and dark condition, respectively. The numbers in the white bars indicate light intensity ( $\mu \mathrm{mol}$ $\mathrm{m}^{-2} \mathrm{~s}^{-1}$ ). Average traces of 3 biological replicate are shown. (c) Values of fluorescence signal at the end of each light intensity irradiation
The reliability of PCI extraction method was further verified using a mutant strain lacking $n d h D 1$ and $n d h D 2$ $(\Delta n d h D 1 / 2)$. In this mutant strain, which lacks the ability to oxidize $\mathrm{NAD}(\mathrm{P}) \mathrm{H}$ in the respiratory chain through the Type I NAD(P)H dehydrogenase complex (NDH-1) (Ohkawa et al. 2000), the relative ratio of NADPH at the dark-adapted state is considered to be as high as that in the light-adapted state (Sétif et al. 2020). In fact, NAD(P)H fluorescence levels did not change when the light was turned on (Fig. 5a, stages I' and II'). Although the fluorescence level decreased transiently after the light was turned off, it quickly recovered to the same level as in the light condition (stage-III'). This behavior was consistent with previous results (Sétif et al. 2020). The PCI extraction
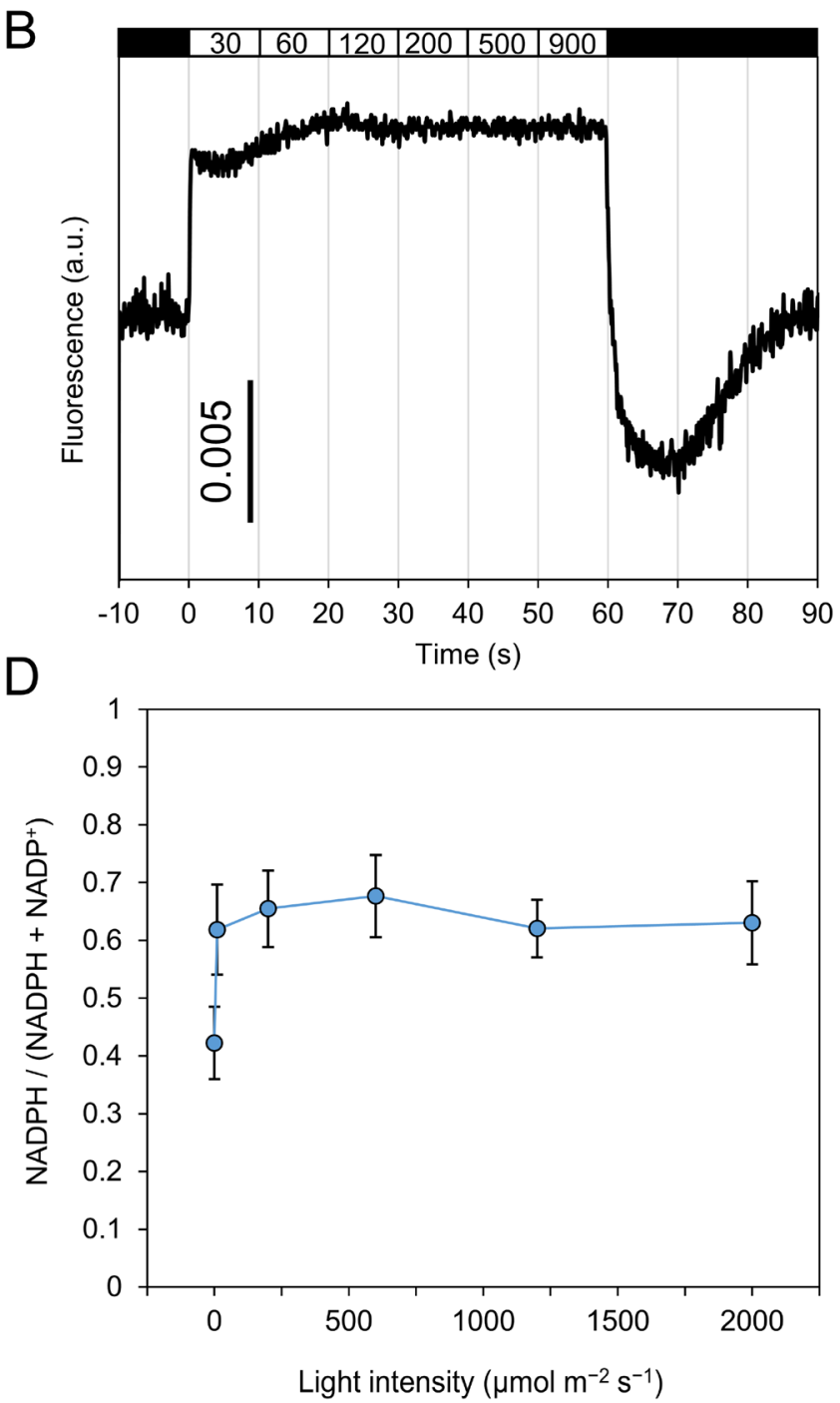

shown in (a) and (b) are plotted. Values are means \pm SD (bars) of 3 biological replicates. (d) NADPH fraction under various light intensities measured by PCI extraction method. Values at 10, 200, 1200 and $2000 \mu \mathrm{mol} \mathrm{m}{ }^{-2} \mathrm{~s}^{-1}$ are means \pm SD (bars) of 4 biological replicates. Values at 0 and $600 \mu \mathrm{mol} \mathrm{m} \mathrm{m}^{-2} \mathrm{~s}^{-1}$ are identical to ones in Fig. $2 \mathrm{c}$ 

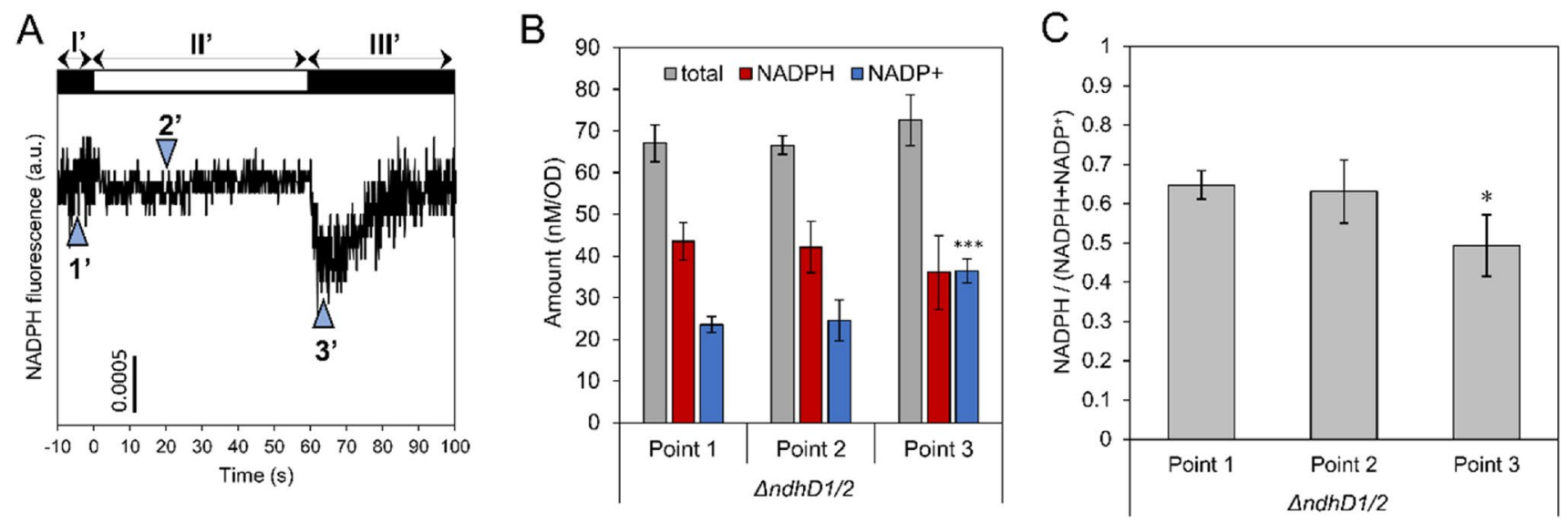

Fig. 5 Light response of $\mathrm{NADP}(\mathrm{H})$ in $\Delta n d h D 1 / 2$ mutant. (a) $\mathrm{NAD}(\mathrm{P})$ $\mathrm{H}$ fluorescence transients affected by 1 min illumination. White and black bars indicate light and dark condition, respectively. Points indicated by triangles with numbers correspond to three different states; point 1: after $1 \mathrm{~h}$ dark adaptation, point 2: $20 \mathrm{~s}$ after light irradiation $\left(200 \mu \mathrm{mol} \mathrm{m}^{-2} \mathrm{~s}^{-1}\right)$, point 3: $3 \mathrm{~s}$ for $\Delta n d h D 1 / 2$ after transition to the dark condition. (b, c) $\mathrm{NADP}(\mathrm{H})$ contents and NADPH fraction against total $\mathrm{NADP}(\mathrm{H})$ content in $\Delta n d h D 1 / 2$ obtained by adding PCI to the cell suspension at each time point. The light intensity of $600 \mu \mathrm{mol} \mathrm{m} \mathrm{m}^{-2} \mathrm{~s}^{-1}$ was used. Values are means \pm SD (bars) of 3 biological replicates. Significant differences from dark-adapted conditions were evaluated by a Student's $t$ test $(* P<0.05, * * * P<0.001)$ method was then applied to the mutant strain for comparison with the results of NAD(P)H fluorescence measurements. For the mutant strain, there was no significant difference in the NADPH fraction between the dark-adapted and light-irradiated points (Figs. 5b, c, points $1^{\prime}$ and $2^{\prime}$ ), whereas a decrease in the NADPH fraction was observed $3 \mathrm{~s}$ after the light was turned off (point $3^{\prime}$ ). This behavior is consistent with that obtained by the NAD $(\mathrm{P}) \mathrm{H}$ fluorescence.

The amount of light-dependent NADPH (difference between points 1 and 2 in Fig. 2a) was overestimated in the fluorescence method. This is because of that the fluorescence yield from intracellular protein-bound NADPH is generally higher than the fluorescence yield from extracellular free NADPH (Latouche et al. 2000). Since the calibration curve was obtained using extracellular free NADPH, the gap between intracellular and extracellular fluorescence yields needs to be corrected. Kauny and Sétif reported that in vivo $\mathrm{NAD}(\mathrm{P}) \mathrm{H}$ fluorescence was estimated to be 2-4 times ('the enhancement factor') higher than the exogenous NADPH fluorescence (Kauny and Sétif 2014). In our results, light-dependent NADPH was estimated to be 20.9 and $9.0 \mathrm{nmol} \mathrm{mg}^{-1} \mathrm{Chl}$ using the fluorescence-based and PCI extraction methods, respectively (Fig. 2 and S2). Thus, the enhancement factor was 2.3 , which is within the range reported by Kauny and Sétif, supporting the reliability of the PCI extraction method.

\section{Discussion}

In photosynthetic organisms, the photochemical reaction causes subcellular dynamic changes of redox state. Considering that Calvin cycle enzymes including GAPDH are arranged peripheral to thylakoid membrane in chloroplasts of higher plants and green algae (Suss et al. 1993, 1995), the diffusion length of photogenerated NADPH would influence on photosynthetic efficiency. Therefore, clarifying the diffusion and localization of photoreduced NADPH in stromal space of cyanobacteria and chloroplasts is important for understanding the photosynthetic reactions. Recent studies using fluorescent protein sensors revealed that the dynamic changes in $\mathrm{NAD}(\mathrm{P}) \mathrm{H}$ are organelle-specific in Arabidopsis thaliana (Lim et al. 2020). On the other hand, dynamics of local redox state within chloroplasts or cyanobacteria (with the size of sub-micrometers), where photosynthetic electron transfer reaction directly changes redox states, is still largely unknown. In the light of this situation, the quantitative information on the redox ratio of $\mathrm{NADP}(\mathrm{H})$ obtained in this study will provide novel insights into the redox dynamics as described below.

Our experimental results clearly show that a fraction of the NADP $(\mathrm{H})$ pool is kept oxidized even in light conditions. Since NADP ${ }^{+}$is an essential co-factor for G6PDH, 6PGDH, ICD and succinic semialdehyde dehydrogenase (Muro-Pastor and Florencio 1992; Zhang and Bryant. 2011; Ishikawa and Kawai-Yamada 2019; Ito and Osanai. 2020), which are components of primary metabolism pathways in Synechocystis, some portion of $\mathrm{NADP}^{+}$pool needs to be stably present even under light conditions. On the other hand, NADPH provides essential reducing power for maintaining antioxidant ability through enzymes such as NTR and GR under both light and dark conditions (Hishiya et al. 2008; Yoshida and Hisabori 2016; Vogelsang and Dietz 2020). Thus, given that $\mathrm{NADP}^{+}$and NADPH have their own distinctive roles in photosynthetic cells, maintaining an appropriate redox 
balance of $\mathrm{NADP}(\mathrm{H})$ pool is expected to be important in facilitating various biological processes cooperatively in fluctuating light environments. For plastoquinone (PQ), one of the major intracellular redox species, it is reported that photoactive and non-photoactive pools exist in both chloroplasts and cyanobacteria (Kruk and Karpinski 2006; Khorobrykh et al. 2020). In fact, we found that non-photoactive PQ accounted for $87 \%$ of the PQ pool in Synechococcus elongatus PCC 7942 cells (Fig. S3). Although NADP(H) is located in the cytoplasm, and cyanobacteria lack organelles, some portion of NADP $(\mathrm{H})$ can be kept oxidized even in light conditions in a cyanobacterial cells by an unknown mechanism. For example, it was reported that NADPH allosterically decreases the binding affinity of ferredoxin $(\mathrm{Fd})$ to ferredoxin-NADP ${ }^{+}$reductase (FNR) (Kimata-Ariga et al. 2019), which may prevent complete reduction of the $\mathrm{NADP}^{+}$pool. Another possible explanation is that NADP $(\mathrm{H})$ non-specifically binds proteins such as Rubisco (Badger and Lorimer 1981; Latouche et al. 2000), which may represent the bulk of the less active NADP $(\mathrm{H})$ pool. Furthermore, the possibility that some proportion of $\mathrm{NADP}(\mathrm{H})$ is spatially sequestered into unknown compartments in cyanobacterial cells cannot be ruled out. Thus, there is room for further investigation toward unveiling the nature of the $\operatorname{NADP}(\mathrm{H})$ pool.

Next, let us consider the reasons for the increase and decrease of the $\mathrm{NAD}(\mathrm{P}) \mathrm{H}$ fluorescence. It is obvious that $\mathrm{NADPH}$ is increased by the reduction of $\mathrm{NADP}^{+}$at the PETC under illumination. The initial decay in $\mathrm{NAD}(\mathrm{P})$ $\mathrm{H}$ fluorescence just after the onset of the dark phase (Fig. 2a, before point 3 in stage-III) can be explained by the increased consumption of NADPH in the Calvin cycle (Kauny and Sétif 2014). The subsequent increase in fluorescence intensity (after point 3 ) is thought to be due to NADPH production by increased OPPP activity. In addition, the $\Delta n d h D 1 / 2$ strain exhibited different time-transient behavior in fluorescence intensity from that observed for the WT (Fig. 5a), indicating that not only the PETC but the respiratory electron transport chain can also lead to light-responsive change in NADP $(\mathrm{H})$ amount. Moreover, as shown in Fig. 5b, the total amount of NADP ${ }^{+}$and NADPH for the mutant was approximately half of that for the WT. On the other hand, since NADH also exhibit fluorescence, it is necessary to verify whether NADH variation also affects typical time transients of NAD $(\mathrm{P})$ $\mathrm{H}$ fluorescence shown in Fig. 2a and reported in previous papers (Mi et al. 2000; Kauny and Sétif 2014; Holland et al. 2015; Shaku et al. 2016). In fact, a recent study for chloroplasts in planta showed that NADH also increased by light irradiation (Lim et al. 2020), raising the above possibility. However, we found that NADH in Synechocystis was hardly changed over the light irradiation for at least one minute (Fig. 3). Taken together, variation of NADPH amount due to activities in the photosynthetic and respiratory electron transport chains, Calvin cycle, and OPPP contributes to the time-transient changes of in vivo $\mathrm{NAD}(\mathrm{P}) \mathrm{H}$ fluorescence at least within one minute.

As described, we have successfully determined the absolute amount of NADP $(\mathrm{H})$ and the NADPH fraction using PCI during the extraction process. The total NADP $(\mathrm{H})$ amount in Synechocystis was estimated as $34.3 \pm 3.4 \mathrm{nmol} \mathrm{mg}^{-1} \mathrm{Chl}$. This value is close to that in chloroplasts of plant protoplasts with high $\mathrm{CO}_{2}$ concentration $\left(19.5 \pm 1.7 \mathrm{nmol} \mathrm{mg}^{-1} \mathrm{Chl}\right.$, Wigge et al. 1993) and in intact chloroplasts of spinach (approximately $40 \mathrm{nmol} \mathrm{mg}{ }^{-1} \mathrm{Chl}$, Lendzian and Bassham 1975). The results obtained using this in vitro method were in very good agreement with the results obtained from the in vivo fluorescence method, demonstrating that this treatment is capable of halting cellular redox within at least a few seconds. This capability is likely to be attributed to the quick inactivation of proteins by phenol, which prohibits further changes in the redox state of NADP $(\mathrm{H})$. Importantly, our quantitative analyses revealed that the some portion of $\operatorname{NADP}(\mathrm{H})$ pool is maintained in oxidized form even in light conditions. In contrast to the PCI extraction method, the methods based on fluorescence protein sensors enable in vivo imaging of redox state. However, since the fluorescence yield is easily influenced by various environmental factors such as local $\mathrm{pH}$, the quantitative estimation of the absolute concentration and redox ratio is, in general, technically difficult (Lim et al. 2020; Sugiura et al. 2020). Thus, there is a complementary relationship between the fluorescent-based in vivo method and our quantitative in vitro method. We anticipate our novel protocol for $\mathrm{NADP}(\mathrm{H})$ quantification established in the present work will deepen our understanding of the regulation mechanisms and physiology of photosynthesis.

Supplementary Information The online version contains supplementary material available at https://doi.org/10.1007/s11120-021-00835-1.

Acknowledgments We thank Dr. Ohkawa (Hirosaki University) and Prof. K. Sonoike (Waseda University) for kindly providing the mutant used in this work. This work was partially supported by the Advanced Low Carbon Technology Research and Development Program (JPMJAL1402) of the Japan Science and Technology Agency (JST), and JSPS KAKENHI Grant Number 18J20176 and 20J00105.

Author contributions K.T., G.S., and S.N. designed research; K.T., G.S., and H.T. performed research; K.T., G.S., H.T., S.K. and S.N. analyzed data; and K.T., G.S., C.M., and S.N. wrote the paper.

\section{Declarations}

Conflicts of interest The authors declare that they have no conflict of interest. 
Open Access This article is licensed under a Creative Commons Attribution 4.0 International License, which permits use, sharing, adaptation, distribution and reproduction in any medium or format, as long as you give appropriate credit to the original author(s) and the source, provide a link to the Creative Commons licence, and indicate if changes were made. The images or other third party material in this article are included in the article's Creative Commons licence, unless indicated otherwise in a credit line to the material. If material is not included in the article's Creative Commons licence and your intended use is not permitted by statutory regulation or exceeds the permitted use, you will need to obtain permission directly from the copyright holder. To view a copy of this licence, visit http://creativecommons.org/licenses/by/4.0/.

\section{References}

Badger MR, Lorimer GH (1981) Interaction of sugar phosphates with the catalytic site of ribulose-1,5-bisphosphate carboxylase. Biochemistry 20:2219-2225

Cooley JW, Vermaas WF (2001) Succinate dehydrogenase and other respiratory pathways in thylakoid membranes of Synechocystis sp. strain PCC 6803: capacity comparisons and physiological function. J Bacteriol 183:4251-4258

Grimme LH, Boardman NK (1972) Photochemical activities of a particle fraction $\mathrm{P} 1$ obtained rom the green alga Chlorella fusca. Biochem Biophys Res Commun 49:1617-1623

Hishiya S, Hatakeyama W, Mizota Y, Hosoya-Matsuda N, Motohashi K, Ikeuchi M, Hisabori T (2008) Binary reducing equivalent pathways using NADPH-thioredoxin reductase and ferredoxinthioredoxin reductase in the cyanobacterium Synechocystis sp. strain PCC 6803. Plant Cell Physiol 49:11-18

Holland SC, Kappell AD, Burnap RL (2015) Redox changes accompanying inorganic carbon limitation in Synechocystis sp. PCC 6803. Biochim Biophys Acta 1847:355-363

Ishikawa Y, Miyagi A, Haishima Y, Ishikawa T, Nagano M, Yamaguchi M, Hihara Y, Kawai-Yamada M (2016) Metabolomic analysis of NAD kinase-deficient mutants of the cyanobacterium Synechocystis sp. PCC 6803. J Plant Physiol 205:105-112

Ishikawa Y, Kawai-Yamada M (2019) Physiological significance of NAD kinases in cyanobacteria. Front Plant Sci 10:847

Ishikawa Y, Miyagi A, Ishikawa T, Nagano M, Yamaguchi M, Hihara Y, Kaneko Y, Kawai-Yamada M (2019) One of the NAD kinases, sll1415, is required for the glucose metabolism of Synechocystis sp. PCC 6803. Plant J 98:654-666

Ito S, Osanai T (2020) Unconventional biochemical regulation of the oxidative pentose phosphate pathway in the model cyanobacterium Synechocystis sp. PCC 6803. Biochem J 477:1309-1321

Kauny J, Sétif P (2014) NADPH fluorescence in the cyanobacterium Synechocystis sp. PCC 6803: a versatile probe for in vivo measurements of rates, yields and pools. Biochim Biophys Acta 1837:792-801

Kern SE, Price-Whelan A, Newman DK (2014) Extraction and measurement of $\mathrm{NAD}(\mathrm{P})(+)$ and $\mathrm{NAD}(\mathrm{P}) \mathrm{H}$. Methods Mol Biol 1149:311-323

Khorobrykh S, Tsurumaki T, Tanaka K, Tyystjärvi T, Tyystjärvi E (2020) Measurement of the redox state of the plastoquinone pool in cyanobacteria. FEBS Lett 594:367-375

Kimata-Ariga, Chikuma Y, Saitoh T, Miyata M, Yanagihara Y, Yamane $\mathrm{K}$, Hase T (2019) NADP $(\mathrm{H})$ allosterically regulates the interaction between ferredoxin and ferredoxin-NADP+ reductase. FEBS Open Bio 9:2126-2136

Kruk J, Karpinski S (2006) An HPLC-based method of estimation of the total redox state of plastoquinone in chloroplasts, the size of the photochemically active plastoquinone-pool and its redox state in thylakoids of Arabidopsis. Biochim Biophys Acta 1757:1669-1675

Latouche G, Cerovic ZG, Montagnini F, Moya I (2000) Light-induced changes of NADPH fluorescence in isolated chloroplasts: a spectral and fluorescence lifetime study. Biochim Biophys Acta 1460:311-329

Lendzian K, Bassham JA (1975) Regulation of glucose-6-phosphate dehydrogenase in spinach chloroplasts by ribulose 1,5-diphosphate and NADPH/NADP ${ }^{+}$ratios. Biochim Biophys Acta 396:260-275

Lim SL, Voon CP, Guan X, Yang Y, Gardeström P, Lim BL (2020) In planta study of photosynthesis and photorespiration using NADPH and NADH/NAD+ fluorescent protein sensors. Nat Commun 11:3238

Mi H, Klughammer C, Schreiber U (2000) Light-induced dynamic changes of NADPH fluorescence in Synechocystis PCC 6803 and its ndhB-defective mutant M55. Plant Cell Physiol 41:1129-1135

Muro-Pastor MI, Florencio FJ (1992) Purification and properties of NADP-isocitrate dehydrogenase from the unicellular cyanobacterium Synechocystis sp. PCC 6803. Eur J Biochem 203:99-105

Ohkawa H, Pakrasi HB, Ogawa T (2000) Two types of functionally distinct NAD(P)H dehydrogenases in Synechocystis sp. strain PCC6803. J Biol Chem 275:31630-31634

Osanai, Oikawa A, Shirai T, Kuwahara A, Iijima H, Tanaka K, Ikeuchi M, Kondo A, Saito K, Hirai MY (2014) Capillary electrophoresismass spectrometry reveals the distribution of carbon metabolites during nitrogen starvation in Synechocystis sp. PCC 6803. Environ Microbiol 16:512-524

Raines CA (2003) The Calvin cycle revisited. Photosynth Res 75:1-10

Sétif P, Shimakawa G, Krieger-Liszkay A, Miyake C (2020) Identification of the electron donor to flavodiiron proteins in Synechocystis sp. PCC 6803 by in vivo spectroscopy. Biochim Biophys Acta Bioenerg 1861:148256

Shaku K, Shimakawa G, Hashiguchi M, Miyake C (2016) Reductioninduced suppression of electron flow (RISE) in the photosynthetic electron transport system of Synechococcus elongatus PCC 7942. Plant Cell Physiol 57:1443-1453

Shimakawa G, Shaku K, Miyake C (2018) Reduction-induced suppression of electron flow (RISE) is relieved by non-ATP-consuming electron flow in Synechococcus elongatus PCC 7942. Front Microbiol 9:886

Sugiura K, Mihara S, Fu N, Hisabori T (2020) Real-time monitoring of the in vivo redox state transition using the ratiometric redox state sensor protein FROG/B. Proc Natl Acad Sci USA 117:16019-16026

Suss KH, Arkona C, Manteuffel R, Adler K (1993) Calvin cycle multienzyme complexes are bound to chloroplast thylakoid membranes of higher plants in situ. Proc Natl Acad Sci USA 90:5514-5518

Suss KH, Prokhorenko I, Adler K (1995) In situ association of Calvin cycle enzymes, ribulose-1,5-bisphosphate carboxylase/oxygenase activase, ferredoxin-NADP ${ }^{+}$reductase, and nitrite reductase with thylakoid and pyrenoid membranes of Chlamydomonas reinhardtii chloroplasts as revealed by immunoelectron microscopy. Plant Physiol 107:1387-1397

Takahashi H, Uchimiya H, Hihara Y (2008) Difference in metabolite levels between photoautotrophic and photomixotrophic cultures of Synechocystis sp. PCC 6803 examined by capillary electrophoresis electrospray ionization mass spectrometry. J Exp Bot 59:3009-3018

Tamoi M, Miyazaki T, Fukamizo T, Shigeoka S (2005) The Calvin cycle in cyanobacteria is regulated by $\mathrm{CP} 12$ via the $\mathrm{NAD}(\mathrm{H}) /$ NADP $(H)$ ratio under light/dark conditions. Plant J 42:504-513

Vogelsang L, Dietz KJ (2020) Regulatory thiol oxidation in chloroplast metabolism, oxidative stress response and environmental signaling in plants. Biochem J 477:1865-1878 
Wigge B, Krömer S, Gardeström P (1993) The redox levels and subcellular distribution of pyridine nucleotides in illuminated barley leaf protoplasts studied by rapid fractionation. Physiol Plant 88:10-18

Yoshida K, Hisabori T (2016) Two distinct redox cascades cooperatively regulate chloroplast functions and sustain plant viability. Proc Natl Acad Sci USA 113:E3967-3976

Zhang S, Bryant DA (2011) The tricarboxylic acid cycle in cyanobacteria. Science 334:1551-1553
Publisher's Note Springer Nature remains neutral with regard to jurisdictional claims in published maps and institutional affiliations. 